\title{
Contribuições para a gestão estratégica de instituições de ciência e tecnologia
}

\author{
Hernan Edgardo Contreras Alday ${ }^{\mathrm{a}, *}$, José Antonio Arantes Salles ${ }^{\mathrm{b}}$ \\ a,*hernanc@terra.com.br, FESPSP, Brasil \\ bjasalles@terra.com.br, UNINOVE, Brasil
}

\begin{abstract}
Resumo
Este trabalho apresenta contribuições para a gestão estratégica das instituições de ciência e tecnologia baseadas em uma das configurações de Mintzberg integrada a um sistema de avaliação de desempenho com indicadores adequados à natureza deste modelo de organização. Para desenvolver essa perspectiva, foi realizado um levantamento da literatura sobre modelos de gestão e sistemas de avaliação de desempenho, bem como sobre a gestão das instituições de ciência e tecnologia - C\&T no Brasil, notadamente na identificação dos stakeholders dessas organizações. Foi aplicado um questionário junto aos líderes de pesquisa na instituição de C\&T selecionada, e foram realizadas entrevistas com seus gestores, para analisar os resultados obtidos e para discutir a aplicabilidade da proposta para a gestão daquela instituição. Os resultados demonstraram que a proposta de um sistema de gestão baseado na configuração adhocrática associado a um sistema de medição de desempenho do tipo do Balanced Scorecard tem aplicabilidade nas instituições de C\&T.
\end{abstract}

Palavras-chave

Gestão estratégica. Sistemas de avaliação de desempenho. Configurações de Mintzberg. Instituições de ciência e tecnologia.

\section{Introdução}

0 século XX foi um palco de grandes realizações em todos os campos do saber. A administração não é exceção. Apesar de as empresas e sua gestão existirem de forma embrionária desde os primórdios dos tempos, foi somente em 1903 que surgiu o primeiro estudo científico dos métodos de gestão, apresentado sob a forma de uma teoria (FERREIRA, 2002).

A estratégia passou a ocupar espaço no mundo empresarial em meados dos anos 60 , em resposta à obsolescência dos tradicionais planejamentos de médio e longo prazo e à dificuldade de esses instrumentos se adaptarem a um ambiente turbulento, em constante mutação. A partir da década de 80, o enfoque do planejamento estratégico ganhou amplitude, profundidade e complexidade, dando origem à administração estratégica (FERREIRA, 2002).

Ansoff (1990), considerado o pai do planejamento estratégico e da administração estratégica, define estratégia como as regras e diretrizes para decisão que orientam o processo de desenvolvimento de uma organização. Para ele, a administração estratégica compartilha com a administração por objetivos a preocupação com as contínuas mudanças do ambiente externo da empresa. Entretanto, ao passo que a administração por objetivos utiliza os objetivos traçados como base de uma visão global da gestão, a administração estratégica se interessa pelo papel dos objetivos nas decisões estratégicas.

Segundo Hitt et al. (2002), o processo de administração estratégica é representado pelo elenco completo de compromissos, decisões e ações necessárias para que uma empresa alcance a competitividade estratégica e aufira retornos superiores à média.

Por outro lado, as mudanças na orientação da política de C\&T significam também alterações para as instituições de pesquisa. Um dos elementos 
mais significativos é a exigência, feita pelas agências de fomento como condição essencial para o financiamento, de os projetos demonstrarem capacidade de gerar resultados para a indústria.

Isso significa para os pesquisadores a obrigação de pensar e prever as modalidades de apropriação econômica e social dos resultados de suas atividades de pesquisa. A obrigação de prever a vinculação dos projetos a uma demanda - em geral não explicitada pelas empresas, o que a torna de difícil identificação pelos pesquisadores - é consequência direta da leitura do novo cenário econômico mundial feita pelo governo.

A política de C\&T precisa, então, incluir medidas de apoio à inovação para que efetivamente a acumulação de conhecimentos e a inovação se tornem fatores essenciais geradores da dinâmica competitiva.

Para se adaptarem a esse ambiente e aos desafios, as instituições públicas de pesquisa terão de buscar novas formas organizacionais e definir novas modalidades de atuação. Muitas das dificuldades encontradas são relacionadas à tradicional instabilidade financeira das instituições de pesquisa, mas também têm a ver com a escassa experiência em gestão administrativa dos pesquisadores (ZOUAIN, 2001).

0 sistema de avaliação de desempenho nas organizações está se tornando cada vez mais fator de sucesso empresarial como ferramenta de apoio para uma gestão mais eficaz, independentemente do tipo de organização.

No entanto, existe uma perspectiva de que instituições de ciência e tecnologia deveriam ser geridas por modelos exclusivos, mais aplicáveis à gestão pública. É necessário então pesquisar na literatura alternativas para a gestão estratégica de instituições de ciência e tecnologia.

Este artigo pretende analisar e propor contribuições para a gestão estratégica de instituições de ciência e tecnologia, a partir de uma determinada visão organizacional, com base em um sistema de avaliação de desempenho que alie a especificidade das instituições de C\&T com as necessidades de gestão colocadas pelo mercado.

\section{Abordagem metodológica}

Devido ao tema dos modelos de gestão baseados em sistemas de medição de desempenho estar associado à gestão de instituições de ciência e tecnologia, a pesquisa realizada se caracterizou como exploratória e descritiva.
0 estudo exploratório foi útil pelas questões de pesquisa serem inicialmente vagas e também por existir pouca teoria disponivel para orientar as previsões, utilizando-se esse princípio para melhor compreensão do estudo. 0 estudo descritivo é definido por Oliveira (2002) como um tipo de estudo que permite ao pesquisador melhor compreensão do comportamento de diversos fatores e elementos que influenciam determinado fenômeno, sua ordenação e classificação.

Entretanto, o propósito é também fornecer algum subsídio ou base para um modelo que possa contribuir com a teoria, tendo assim um cunho de pesquisa teórica.

Quanto à abordagem da pesquisa, o método de procedimento de pesquisa adotado é a abordagem qualitativa, um guarda-chuva que abriga uma série de técnicas de interpretação que procuram descrever, decodificar, traduzir e qualquer outro termo relacionado com o entendimento e não com a frequência da ocorrência de determinado fenômeno.

Godoy (1995) argumenta que, de maneira diversa (da pesquisa quantitativa), a pesquisa qualitativa não procura enumerar e/ou medir os eventos estudados nem emprega instrumental estatístico na análise dos dados. Ela parte de questões e focos de interesse mais amplos, que vão se definindo à medida que o estudo se desenvolve, procurando compreender os fenômenos segundo a perspectiva dos sujeitos, ou seja, dos participantes da situação em estudo.

A pesquisa foi caracterizada como sendo de natureza descritiva porque utilizou critério estruturado e especificamente criado para medir características descritas envolvendo as seguintes atividades: criar dispositivos para coleta de dados, coletar dados, verificar erros, codificar dados e armazená-los (HAIR et al., 2005).

0 corte desta pesquisa foi de caráter transversal, mesmo porque os estudos descritivos normalmente apresentam um panorama ou uma descrição dos elementos administrativos em dado ponto do tempo, ou seja, dados transversais que são dados coletados em um único ponto no tempo e sintetizados estatisticamente.

Os métodos de procedimento mais comuns para coletar dados na pesquisa qualitativa são a observação participativa, a entrevista semiestruturada e o exame de documentos. Pela análise das alternativas conhecidas, é possível concluir que a abordagem qualitativa é a mais adequada para o desenvolvimento da presente pesquisa, sendo que os critérios que mais 
contribuíram para essa escolha foram adequação aos conceitos envolvidos e adequação aos objetivos da pesquisa.

De acordo com o objetivo do presente artigo, pode-se notar que a pesquisa pretende contribuir para a teoria com o conjunto de objetivos que culminará com a proposta de uma perspectiva de gestão para instituições de ciência e tecnologia.

A seleção da unidade de análise da presente pesquisa foi considerada, além da argumentação teórica, uma instituição de ciência e tecnologia no nível micro. A escolha da empresa ou instituição tem como critério a contribuição teórica que o estudo possa ter para a refutação e/ou acréscimo de elementos do modelo esboçado. Além disso, a empresa a ser estudada deve possuir características relacionadas com a proposta do tema da presente pesquisa e ter a possibilidade de viabilizar o modelo resultante deste estudo.

A empresa selecionada foi escolhida pelos seguintes critérios:

- Em função de sua tipicidade: a empresa deve possuir características específicas em relação à formulação e relevância estratégica na área de ciência e tecnologia;

- Em função de seu tempo de existência/posição no mercado: esse estudo longitudinal exigiu que a empresa apresentasse uma história na aplicação direta no tema de gestão estratégica; $\mathrm{e}$

- Pela facilidade de acesso aos dados: ponto crucial para o desenvolvimento de uma teoria substantiva de qualidade.

A fim de validar os resultados da pesquisa de campo, que tem como objetivo levantar possíveis indicadores de desempenho na instituição escolhida, foram realizadas quatro entrevistas com gestores que representam as diretrizes e ações seguidas por essa instituição e que, dessa forma, pudessem servir de teste para a forma de gestão ora proposta. A coleta de dados pretendeu seguir as seguintes origens:

- Fontes secundárias: referem-se à análise de registros, documentos de fontes privadas ou oficiais, incluindo formulários, relatórios, manuais, entre outros que estiveram relacionados ao objetivo da pesquisa.

0 objetivo da utilização dessas fontes secundárias é a obtenção de mais dados sobre a pesquisa em questão, de forma que possam ratificar e complementar as informações obtidas por intermédio das fontes primárias.

Os dados secundários desta pesquisa foram obtidos por meio de periódicos, livros, trabalhos publicados, acesso à internet das organizações de ciência e tecnologia, além do Plano Diretor 2006-2009 fornecido pela instituição onde foram aplicados os estudos.

A coleta desses dados ocorreu na primeira fase do levantamento, facilitando a obtenção de informações para o entendimento do funcionamento da organização e na elaboração do processo de entrevistas.

- Fontes primárias: são aquelas que têm relação direta com os fatos e a realidade em análise. São dados obtidos no campo pelo pesquisador por meio de questionário específico e de entrevistas semiestruturadas junto aos dirigentes da instituição escolhida para o estudo. Os entrevistados foram intencionalmente escolhidos por representarem pessoas que desempenham o papel de tomadores de decisão na instituição de ciência e tecnologia em estudo.

Portanto, para desenvolver essa proposta de gestão para instituições de ciência e tecnologia foram realizadas as seguintes atividades: análise da literatura buscando identificar as informações sobre a gestão das instituições de C\&T no Brasil; análise dos resultados de um levantamento de campo na instituição de C\&T selecionada quanto a indicadores de desempenho; e análise das entrevistas com os gestores da instituição de C\&T sobre uma proposta de gestão baseada em uma das configurações de Mintzberg integrada a um sistema de avaliação de desempenho construída a partir das etapas anteriores.

\section{Modelos de gestão}

Have et al. (2003) pesquisaram mais de 50 modelos de gestão usados e citados frequentemente. Eles podem ser classificados em linhas gerais como estratégia, organização, processo fundamental, processos funcionais e pessoas e comportamento. Para esses autores, os modelos e teorias oferecem meios de reduzir as complexidades e incertezas envolvidas e não apenas soluções para problemas organizacionais.

Parece evidente que o sucesso da implantação e desenvolvimento de um novo modelo de gestão, bem como de qualquer sistema que implique a participação e/ou envolvimento dos funcionários, requer a confiança recíproca entre funcionários e empresa, entre funcionários e gerentes e executivos etc. (PEREIRA; MIRANDA, 2007).

Segundo Have et al. (2003), os principais modelos de gestão contemporâneos selecionados foram em grande parte resultado de pesquisa literária. Para este estudo, foram considerados os modelos com relação mais direta com o tema da pesquisa, quais sejam: o Balanced Scorecard e as configurações de Minztberg. 


\section{Análise das configurações de Mintzberg}

Cinco mecanismos de coordenação podem abranger as maneiras fundamentais pelas quais as organizações coordenam suas tarefas, isto é: ajustamento mútuo; supervisão direta; padronização dos processos de trabalho; padronização dos resultados; e padronização das habilidades dos trabalhadores. Nestes devem ser considerados os elementos mais fundamentais da estrutura, a cola que mantém as organizações unidas (MINTZBERG et al., 1995, 2006).

0 ajustamento mútuo obtém a coordenação do trabalho pelo processo simples de comunicação informal; debaixo do ajustamento mútuo o controle do trabalho permanece nas mãos dos operadores. Em razão de ser um mecanismo simples de coordenação, o ajustamento mútuo é naturalmente utilizado nas organizações mais simples. Todavia, paradoxalmente, é também empregado em casos mais complexos. Tal atividade exige uma elaboradíssima divisão de trabalho, com milhares de especialistas fazendo todos os tipos de atividades específicas. No início, porém, nenhum está seguro do que exatamente necessita ser feito. Tal conhecimento se desenvolve na proporção que o trabalho se desenrola. Assim, em uma análise final, apesar do uso de outros mecanismos de coordenação, o sucesso do empreendimento depende, preliminarmente, da habilidade dos especialistas em se adaptar cada um com o outro no decurso de suas rotas sem mapas.

Segundo Mintzberg et al. (1995, 2006), as organizações são estruturadas para apreender e dirigir sistemas de fluxos e determinar os interrelacionamentos das diferentes partes. Tais fluxos e inter-relacionamentos dificilmente são de formato linear, com os elementos seguindo ordenadamente um depois do outro. As palavras ainda devem seguir essa forma linear, e disso resulta ser muito difícil descrever a estruturação das organizações exclusivamente com palavras, devendo ser suplementadas com imagens. Assim sendo, é necessário um diagrama básico para representar a própria organização, e que também possa ser tratado de várias maneiras, com o fim de mostrar as diferentes ocorrências capazes de suceder nas organizações e as diversas formas que a organização pode adotar por si mesma.

Segundo Mintzberg et al. (1995, 2006), os mecanismos para coordenar, os parâmetros para delinear e os fatores situacionais, todos eles se encaixam em blocos naturais, as configurações. É o que se conhece como estruturas em cinco configurações: 1) a estrutura simples; 2) a burocracia mecanizada; 3) a burocracia profissional; 4) a forma divisionalizada; e 5) a adhocracia.

Em cada configuração, um dos diferentes mecanismos de coordenação é dominante, uma parte diferente da organização desempenha o papel mais importante e um tipo diverso de descentralização é utilizado.

Geralmente, nas instituições que trabalham com projetos haveria a tendência natural em existir mais projetos do que recursos e capacidades disponíveis, ou a existência de projetos aguardando liberação (SCHELP, 2005 apud SANTOS et al., 2007).

\section{Sistemas de avaliação de desempenho - Balanced Scorecard}

Com o aprimoramento e difusão dos modelos de estratégias empresariais nas últimas três décadas ganharam importância os processos de gerenciamento do desempenho, com a utilização dos sistemas de avaliação de desempenho.

Como resultado de observações empíricas, realizadas ao longo do tempo, verifica-se que uma parcela significativa das empresas dedica mais atenção aos indicadores financeiros, e uma parcela tende a mostrar resultados de curto prazo de fatos já ocorridos, não indicando uma relação mais ampla do tipo causa e efeito.

Uma abordagem eficaz deve buscar transpor essas fronteiras definidas pelos tradicionais indicadores financeiros, pois na maioria dos casos verifica-se que as empresas no seu planejamento estabelecem objetivos e diretrizes estratégicas mais amplos, que não são constituídos somente de elementos de natureza financeira (CAVENAGHI; BRUNSTEIN, 2001).

Um modelo de avaliação empresarial adequado tem de facilitar e permitir o processo de identificação para que os gestores dos recursos possam chegar até a causa dos problemas.

Para que uma organização faça uso efetivo dos resultados da avaliação de desempenho, ela deve possuir também a habilidade de fazer a transição das informações, para avaliação da administração. lsso significa poder antecipar mudanças pontuais necessárias, nas diretrizes estratégicas da organização, e ter uma metodologia para efetuar a mudança estratégica.

Muitas organizações possuem alguma forma de medidas de desempenho, mas precisam iniciar um processo de revisão da medição de desempenho, sendo importante conduzir uma avaliação mais abrangente. lsso poderá ajudar a identificar quais medidas de desempenho podem ser mantidas, 
quais podem ser descartadas e quais devem ser implementadas. Um diagnóstico da medição de desempenho procura verificar como é a medição de desempenho existente na organização e o que é preciso fazer para reestruturá-la de acordo com um modelo de sistemas de medidas de desempenho. 0 diagnóstico procura identificar se o sistema possui todos os elementos apropriados, se tem medidas de melhoria, se tem medidas que relatam objetivos de curto e de longo prazo. Em relação ao ambiente, o diagnóstico avalia se as medidas de desempenho reforçam as estratégias da organização, se elas combinam com a cultura organizacional, se são consistentes com a estrutura de reconhecimento e recompensa, e se algumas focam na satisfação do cliente e na concorrência (FERRAZ; MARTINS, 2002).

Um sistema de indicadores deve examinar não só as várias funções empresariais, mas também ter aptidão de verificar a tendência do desempenho da empresa. Essa tendência deve revelar a propensão de direção e sentido do conjunto de variáveis que a expresse, tanto em relação às funções como da companhia considerada como um todo (ZILBER; FISCHMANN, 2002).

Dentre as metodologias e sistemas de avaliação de desempenho conhecidos, identificam-se no Balanced Scorecard os elementos necessários para se alcançar os objetivos, na utilização de indicadores de desempenho. O BSC apoia-se num conjunto de conceitos que identificam as dimensões financeiras e não financeiras, internas e externas, parciais e globais.

A estruturação do BSC tem como ponto inicial a interpretação da estratégia, identificando os objetivos pretendidos. Em seguida, de acordo com o objetivo, define-se qual o fator crítico de sucesso desse objetivo - o que deve ser realizado para se alcançar o objetivo pretendido - para atender a estratégia definida. Uma vez identificado o fator-chave para o desempenho, com sucesso da atividade, deve-se escolher a melhor medida, para acompanhar o desempenho e qual meta que deve ser alcançada (SALLES, 1998).

Cada um dos objetivos estratégicos identificados como essenciais para que a empresa alcance o seu melhor resultado empresarial deve ser classificado nas quatro dimensões - financeira, cliente, processos internos, aprendizado e crescimento propostas pelo modelo do BSC.

As quatro perspectivas do scorecard equilibram os objetivos de curto e longo prazo, os resultados desejados e os vetores do desempenho desses resultados, as medidas objetivas concretas e as medidas subjetivas mais imprecisas. Embora a multiplicidade de medidas que o Balanced Scorecard contém possa parecer confusa, scorecards bem elaborados se caracterizam pela unidade de propósito, posto que todas as medidas apontam para a execução de uma estratégia integrada (KAPLAN; NORTON, 1997).

\section{Gestão de instituições de ciência e tecnologia}

Segundo Bertero (1994), a gestão e condução dos esforços que em nosso país objetivaram o desenvolvimento científico e tecnológico sempre foram de iniciativa governamental e consequentemente ocorreram num contexto de administração pública e com a presença quase exclusiva do Estado.

Ainda segundo Bertero (1994), na medida em que políticas e gestão de ciência e tecnologia estão a cargo do setor público é impossível avaliar a qualidade administrativa das instituições voltadas à gestão e à formulação de política científica e tecnológica sem uma análise, mesmo que breve, das limitações e obstáculos que afetam a administração pública brasileira:

- A administração pública brasileira nunca atingiu de maneira integral um padrão burocrático clássico que foi distintivo de alguns países, dentre os quais se destacam pela influência que exerceram e pela limpidez do modelo França e Alemanha;

- Em tal sistema a sociedade não se relaciona com a administração pública enquanto conjunto de cidadãos, mas como "clientela" potencialmente capaz de extrair favores e benefícios; e

- A medição de desempenho, produtividade e eficiência em administração constitui um problema e desafia permanentemente profissionais de administração.

0 setor público enfrenta dificuldades maiores quanto ao estabelecimento de critérios:

- Na área de C\&T a descontinuidade vem sendo apontada frequentemente como um dos principais problemas atuais.

Responsável pela formulação e implementação da Política Nacional de Ciência e Tecnologia, o Ministério da Ciência e Tecnologia (MCT) tem suas ações pautadas na busca e aprimoramento dos instrumentos que levem ao desenvolvimento científico-tecnológico, econômico e social do país.

As chamadas organizações baseadas na pesquisa - sejam laboratórios que somente se dedicam a ela, sejam corporações na indústria de tecnologia de ponta que são grandemente afetadas 
pelos seus esforços de pesquisa - são dirigidas para a configuração da adhocracia pelo motivo do seu trabalho ser complexo pela própria natureza. Mesmo hospitais e universidades são direcionados para a adhocracia quando se engajam na verdadeira pesquisa inovadora.

Segundo Zouain (2001), diferentemente das empresas, os institutos de pesquisa tecnológica não podem ser julgados simplesmente com base nas ações ou lucros do mercado. Boa parte do investimento nesses institutos corresponde a gastos derivados de bens públicos, a longo prazo.

Este artigo procura contribuir para a gestão de instituições de ciência e tecnologia. A proposta busca revelar, por meio de indicadores de desempenho, as interações que ocorrem nessa área, fornecendo uma apreciação das suas necessidades além das perspectivas produtivas e financeiras. A base inicial para a definição de uma perspectiva de gestão será a de definir uma configuração segundo as proposições de Mintzberg et al. (1995, 2006), aliada aos indicadores de desempenho considerados mais adequados para esse tipo de instituição, baseados num modelo como o do Balanced Scorecard.

No caso da Empresa Brasileira de Pesquisa Agropecuária - Embrapa, um conjunto de indicadores potenciais de produção está disponível desde 1991. A partir dos planos anuais de trabalho, que refletem as variações de produção dos centros de pesquisa, chegou-se a um conjunto de 28 variáveis de produto e três de insumo representativas do processo produtivo da Embrapa (SOUZA et al., 2007).

A fim de poder verificar o sistema proposto de gestão de uma instituição de C\&T, foi realizada uma pesquisa no Laboratório Nacional de Luz Síncrotron - LNLS, instalado em Campinas, sendo o único do gênero existente no Hemisfério Sul, instituição de referência nacional e internacional na pesquisa da luz síncrotron.

\section{A instituição pesquisada}

o LNLS, em 1987, começou a realizar um ambicioso projeto: colocar o Brasil num seleto grupo de países capazes de produzir luz síncrotron. O objetivo foi alcançado e, desde julho de 1997, centenas de pesquisadores, do Brasil e do exterior, utilizam a fonte brasileira de luz síncrotron para fazer pesquisas que visam desbravar novas fronteiras de conhecimento sobre os átomos e as moléculas.

Luz síncrotron é a intensa radiação eletromagnética produzida por elétrons de alta energia num acelerador de partículas. A luz síncrotron abrange uma ampla faixa do espectro eletromagnético: raios $\mathrm{X}$, luz ultravioleta $\mathrm{e}$ infravermelha, além da luz visível, que sensibiliza o olho humano, são emitidos pela fonte. É com essa luz que cientistas estão descobrindo novas propriedades físicas, químicas e biológicas existentes em átomos e moléculas, os componentes básicos de todos os materiais.

As pesquisas realizadas no LNLS são o passo inicial que pode levar ao desenvolvimento de novos materiais de alto desempenho - mais econômicos e menos nocivos ao ambiente - e a novos conhecimentos sobre materiais biológicos, como as proteínas, que irão propiciar mais adiante o surgimento de soluções para problemas de saúde.

Isso faz com que a empresa escolhida assuma um interesse muito especial do pesquisador, para esse tipo de trabalho, considerando a grande variedade de enfoque que atualmente se dá ao tópico motivo da pesquisa. Houve, ainda, a preocupação em desenvolver um estudo que proporcionasse não apenas subsídios do ponto de vista acadêmico, mas também que agregasse elementos constitutivos de relevância para um estudo prático.

Os entrevistados desta pesquisa foram os pesquisadores e técnicos líderes de grupos e equipes de trabalho do Laboratório Nacional de Luz Síncrotron. Foi solicitada a essa organização a relação dos principais grupos de trabalho de onde foram recebidos 15 questionários dos quase 40 grupos existentes e que constituíram a principal fonte de pesquisa. 0 número 15 é considerado representativo, pois segundo autores como Fonseca e Martins (1996, apud FERRAZ; MARTINS, 2002) e Dowling e Clark (2000) a amostragem de 15 entrevistados, que equivale a aproximadamente $1 / 3$ do número de pesquisadores e líderes de equipes, torna-se representativa para esta pesquisa em relação aos dados que foram coletados.

- Os dados primários obedeceram a algumas etapas: a criação de um instrumento de coleta de dados, a coleta de dados, a codificação, verificação de dados e a análise e interpretação deles. Os dados primários coletados nesta pesquisa são os obtidos sobre o LNLS e os dados recolhidos durante a pesquisa através do questionário; $\mathrm{e}$

- Os dados secundários foram fornecidos pela própria instituição, seja na forma de material de divulgação, bem como através do Plano Diretor 2006-2009 também gentilmente fornecido pela sua diretoria e que estarão relacionados na sua fundamentação teórica.

0 questionário foi composto por 34 perguntas, divididas em quatro partes: a primeira parte contendo seis questões teve a finalidade de identificar o perfil 
dos entrevistados; uma segunda, que contemplou oito perguntas, teve por objetivo colher dados sobre a perspectiva dos processos internos; a terceira parte, com 15 perguntas, visou levantar dados a respeito da perspectiva de aprendizado e crescimento; e a quarta parte, contendo cinco perguntas, teve a finalidade de colher dados sobre os processos administrativos da instituição.

Nas últimas três partes do questionário, além das perguntas fechadas, foi deixado espaço para opiniões abertas a fim de avaliar as respostas através da combinação de várias características qualitativas, que são a descrição de coisas sem atribuição direta de números. Estes normalmente são coletados utilizando-se algum tipo de entrevista não estruturada, em uma variável quantitativa, que são mensurações em que números são usados diretamente para representar as propriedades de algo que, como são registrados diretamente com números, os dados ficam de uma forma que facilita uma análise estatística, no caso a média (GOOD; HATT, 1979).

Parte dos dados obtidos na pesquisa foi tabulada em planilha eletrônica e tratada estatisticamente. A escala de Likert é qualificada pelos autores Hair et. al (2005) como métrica e de classificações somadas. Essa classificação procurou mensurar atitudes ou opiniões, e tem esse nome porque obtemos resultados ao somar todas as escalas, que possuem de três a sete pontos, no caso desta pesquisa cinco, para avaliar a intensidade com que alguém concorda com um conjunto de afirmações. A utilização de cinco pontos foi o critério quanto à necessidade de maior precisão para as respostas obtidas.

0 questionário foi aplicado de forma eletrônica via e-mail. Para Gunther (1999), além de os benefícios serem mais rápidos, Schaefer e Dillman (1998) relatam em sua obra um experimento contrastando diferentes maneiras de contato com respondentes, chegando à conclusão de que técnicas utilizadas em aplicações de questionários por correio são igualmente válidas para a aplicação por e-mail.

\section{Análise das informações obtidas por meio do questionário}

$\mathrm{Na}$ primeira parte do questionário foram solicitados dados do perfil dos entrevistados, constituído por 15 profissionais que, na sua grande maioria, lideram grupos de pesquisa da instituição em estudo, bem como outros que fazem parte do departamento de engenharia.

Dos 45 questionários enviados, foram devolvidos devidamente preenchidos 15 deles, o que significa uma amostra de algo em torno de
$30 \%$, que é considerado um número significativo e representativo do universo escolhido para a pesquisa.

Essa limitação foi mitigada pelo fato que se utilizaram, também, entrevistas com os líderes que complementaram os questionários.

Os resultados da primeira parte do questionário mostraram o perfil dos entrevistados, onde $80 \%$ correspondem ao sexo masculino e $20 \%$ ao feminino; a idade mostra que 46,7\% têm idade entre 35 e 44 anos, $40 \%$ acima de 44 anos e 13,3\% idade de 25 a 34 anos. Os entrevistados casados correspondem a $86,7 \%$ e os solteiros a 13,3\%, sendo seu nível de formação $26,6 \%$ doutores, 6,7\% mestres, 6,7\% especialistas e 20\% graduados, mostrando ainda que 40\% deles têm outra formação, tais como pós-doutorado 20\%, doutorando 6,7\% e técnico 13,3\%. A primeira parte mostrou também que 21,4\% dos entrevistados têm até cinco anos de pesquisador, $14,2 \%$ de cinco a dez anos de pesquisador, 43\% têm de 10 a 20 anos de pesquisador e 21,4\% acima de 20 anos de pesquisador. Da mesma forma, a pesquisa mostra no perfil do entrevistado que o tempo de casa, no LNLS, corresponde a $20 \%$ com até 5 anos, 6,7\% de 5 a 10 anos, $60 \%$ de 10 a 20 anos e 13,3\% acima de 20 anos de casa.

$\mathrm{Na}$ segunda parte do questionário, com oito questões, aplicou-se um questionário semiestruturado com o uso do instrumento da escala de likert, onde se procurou identificar aspectos sobre os processos internos da organização (Figura 1).

$\mathrm{Na}$ terceira parte do questionário, com 15 questões, aplicou-se um questionário similar semiestruturado, com o uso da escala de Likert, onde se procurou identificar aspectos sobre a perspectiva de aprendizado e crescimento (Figura 2).

$\mathrm{Na}$ quarta parte do questionário, com cinco questões, aplicou-se também um questionário semiestruturado com o uso do instrumento da escala de Likert, onde se procurou identificar aspectos sobre os processos administrativos da instituição (Figura 3).

A falta de conhecimento dos entrevistados em relação a sistemas de desempenho deve-se ao fato de que a organização não utiliza sistemas de avaliação conhecidos e sim um sistema próprio com uma grande dose de análise de cunho subjetivo. Outro ponto negativo encontrado foi a falta de autonomia nos processos administrativos dos membros das equipes, provavelmente porque a própria estrutura da instituição separa a parte administrativa da parte técnica. 
Entretanto, a grande maioria dos indicadores apresentou resultados favoráveis em relação aos processos internos e, principalmente, aos processos de aprendizado, devido ao alto nível de preparação dos membros das equipes.
Diante dos resultados acima, em relação às questões formuladas aos entrevistados, podemos assumir inicialmente as seguintes conclusões:

As equipes também estão capacitadas para realizar um desenho de estratégias de ação mais

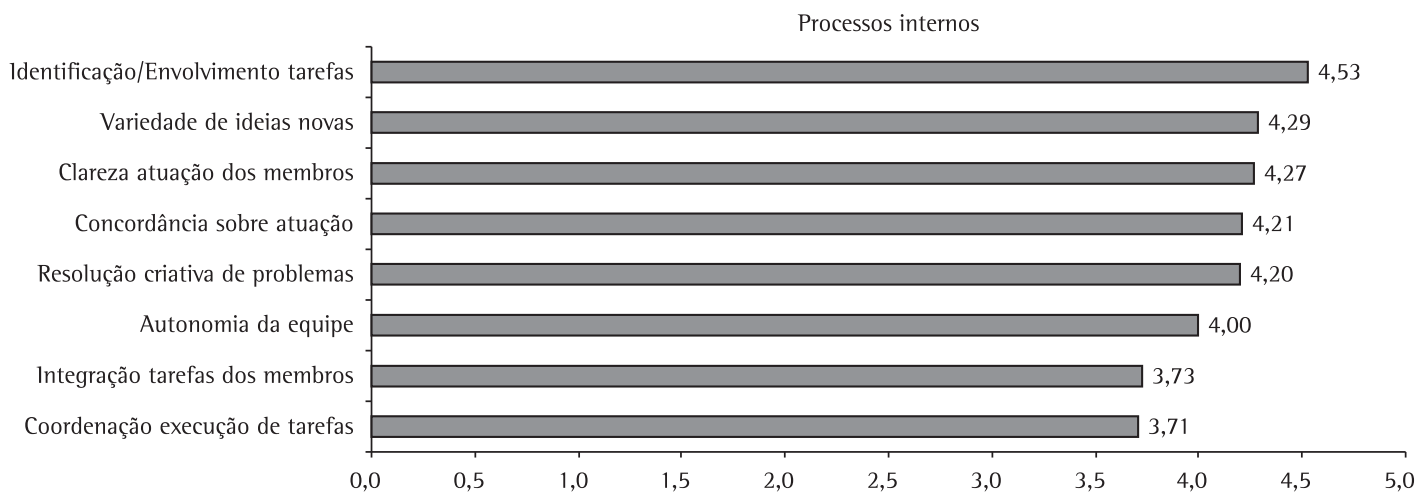

Figura 1. Processos internos. Fonte: primária dos autores.

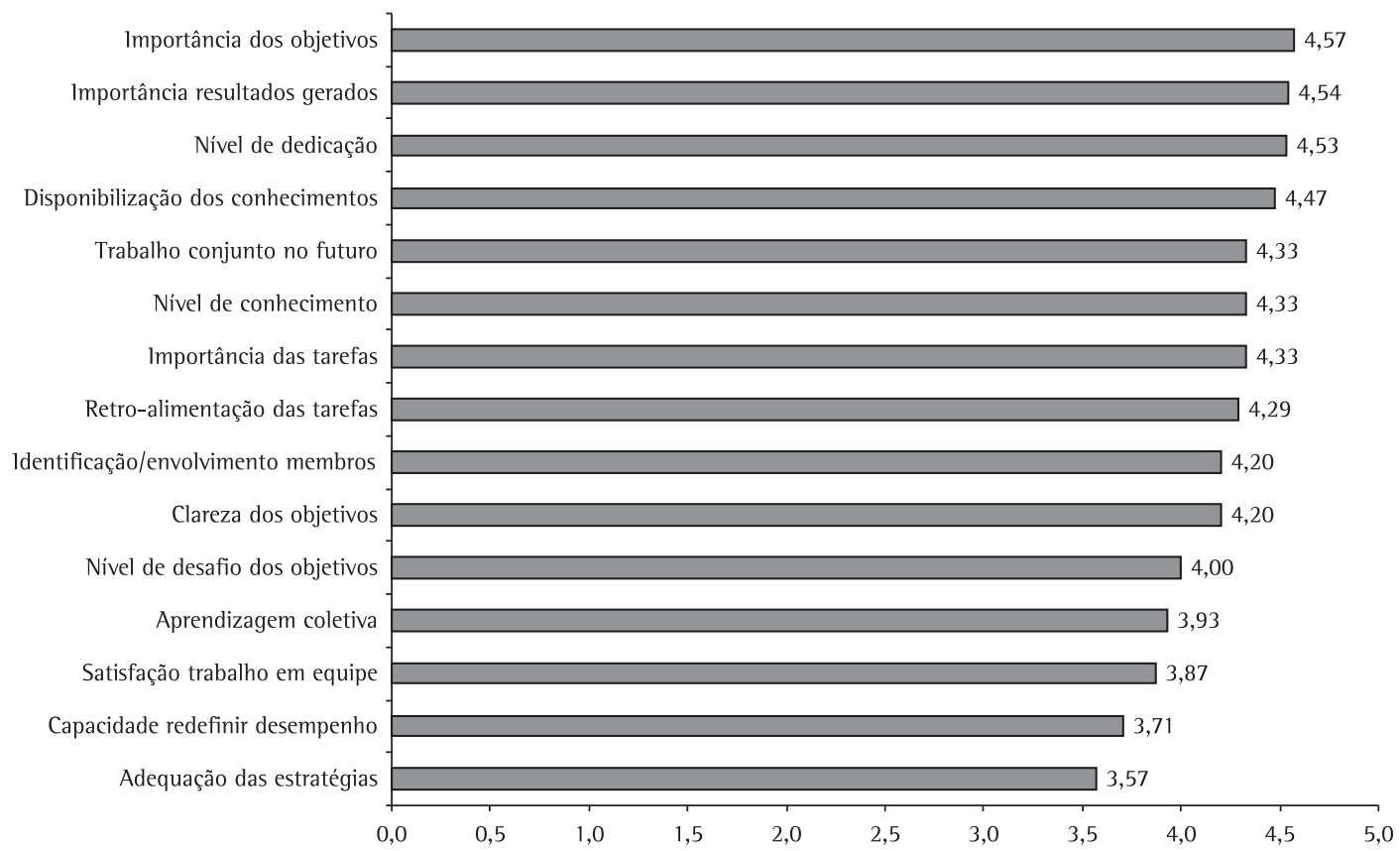

Figura 2. Aspectos de aprendizado. Fonte: primária dos autores.

Procedimentos administrativos

Procedimentos administrativos atuais

Existência sistemas de avaliação

Participação/Contribuição avaliação

Autonomia decisões administrativas

Conhecimento avaliação desempenho

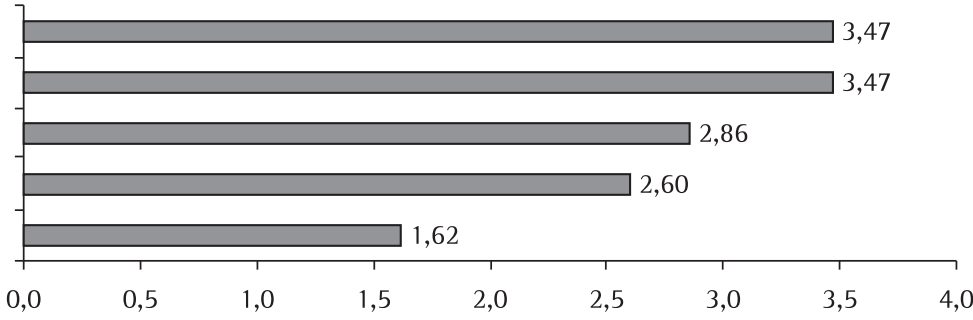

Figura 3. Procedimentos administrativos. Fonte: primária dos autores. 
eficiente, como forma de garantir sua eficiência interna. A criatividade, na busca de soluções originais, deve ser incentivada e tratada como habilidade a ser também adquirida, pelas equipes, por meio de capacitação.

A cultura da organização apresentou-se como importante fator crítico, em especial no que se refere ao compartilhamento de informações e atitude em relação a possíveis mudanças no sistema de avaliação, assim como na consideração dos valores organizacionais.

\section{Análise das informações obtidas por meio de entrevistas com os gestores do LNLS}

Foram entrevistados quatro dirigentes que tomam decisões nos níveis estratégico (2 diretores), tático (1 gerente) e operacional ( 1 líder e pesquisador) do Laboratório Nacional de Luz Síncrotron - LNLS.

Foi utilizado o método de análise de conteúdo que, de acordo com Bardin (1977), é um conjunto de instrumentos metodológicos cada vez mais sutis, em constante aperfeiçoamento, que se aplicam a "discursos" extremamente diversificados.

Sobre os fatores críticos de sucesso da empresa, há certa somatória de fatores nas respostas dos entrevistados em relação aos fatores críticos de sucesso da instituição, com pontos de vista que refletem a prioridade que cada um deles dá aos fatores mencionados, inclusive o nível de informação que cada um tem sobre os fatores críticos de sucesso.

"Acho que tem alguns fatores críticos que enfatizaria: primeiro uma visão de longo prazo, sempre houve uma visão de longo prazo por parte da direção e por parte das pessoas responsáveis pelo laboratório."

Sobre o modelo de gestão atual da instituição, os entrevistados destacaram a responsabilidade do sucesso da gestão para os gestores, mas também com o controle dos processos. Os instrumentos de flexibilidade, autonomia e responsabilidade pela gestão se tornaram mais relevantes, sendo que é um modelo de gestão que se aproxima muito mais de entidades privadas do que públicas. Assim, percebe-se pelas declarações dos entrevistados um modelo um tanto híbrido que, por um lado, é uma empresa privada, mas, por outro, conta com recursos públicos.

“A gestão nossa é bem peculiar, é uma organização social através de um contrato de gestão com o MCT; é algo que foi desenvolvido dentro desse laboratório em 93, que começou a ser pensado porque havia muita clareza que um laboratório como esse exige uma dinâmica de funcionamento que o modelo de administração direta, pública, não satisfaria."

Sobre aspectos positivos e negativos do atual modelo, fica muito claro identificar os aspectos positivos indicados pelos entrevistados; por exemplo, autonomia sobre os quatro grandes processos (controle, compra e venda, contratação e demissão de pessoal); a ideia de autonomia aos gestores, o que permite flexibilidade e rapidez de resposta; possibilidade de combinação de técnicas utilizadas na administração privada; autonomia na área de compras; e contratação de pessoal.

Com relação aos aspectos negativos, os entrevistados citam principalmente a dificuldade de compreensão, por parte de alguns órgãos do governo, que identificam o laboratório como terceirização. Também um dos entrevistados cita como ponto negativo do modelo adotado uma complexidade muito grande para as instituições de pesquisa, em geral, de fazer adequada mensuração de desempenho.

Sobre as medidas de desempenho como parte integrante do sistema de gestão, as medidas de desempenho que a maioria dos entrevistados identifica e reconhece como parte integrante do modelo de gestão são o cumprimento dos itens constantes do contrato de gestão com o MCT, com indicadores que medem as metas do contrato, mas que reconhecem que o processo de decisão é bastante centralizado; não existe ainda um casamento entre os indicadores do contrato de gestão com o sistema de avaliação interna. Uma das medidas de desempenho importante para o síncrotron é a confiabilidade do equipamento sofisticado; é uma medida de desempenho que compõe o modelo de gestão.

" 0 contrato de gestão de metas tem indicadores, faz parte do processo de concessão desse contrato de gestão, então temos indicadores que medem a execução das metas estabelecidas pelo contrato."

Sobre o sistema atual de medição de desempenho, percebe-se que não existe um sistema de avaliação organizado que possa responder às necessidades de alinhamento com as estratégias e objetivos da instituição. 0 sistema existente é um encontro anual junto com o funcionário, para tentar chegar a um consenso, o que seria totalmente errado, de acordo com um dos entrevistados.

"Não temos uma avaliação anual com os funcionários, mas queremos aprimorar ela, fazer com que essa avaliação tenha uma relação mais direta com os indicadores externos de desempenho. lsso que está faltando, temos que melhorar bastante nisso." 
Sobre a utilização das informações do sistema, percebe-se uma série de contradições talvez como resultado da não existência de um sistema de avaliação de desempenho muito claro ou realizado formalmente. As recomendações das avaliações anteriores servem como inputs para o aprimoramento dos fatores internos de gestão, segundo um dos entrevistados, onde cada grupo tem um líder; esse líder avalia seus liderados e a direção avalia seus líderes.

Sobre as características necessárias de um novo modelo de gestão, pode-se observar que, apesar de algumas discrepâncias e aspectos considerados como defesa do fato de não possuir um bom sistema de avaliação de desempenho, a proposta no geral foi considerada aplicável com algumas adaptações em função das características, principalmente culturais, da instituição.

"A proposta parece ser interessante, mas deveria sofrer adaptações e as pessoas do laboratório precisam ser convencidas, porque o sistema BSC é algo que elas não conhecem, devem ser utilizados indicadores adequados para a instituição."

Pelas respostas obtidas dos entrevistados, em relação aos fatores críticos de sucesso da instituição, observa-se, de maneira geral, um grande reconhecimento pela história da instituição. Os entrevistados valorizam a construção do laboratório e sua participação no projeto do síncrotron até a presente data.

Observa-se também a valorização, por parte dos entrevistados, da estratégia da constituição do laboratório, uma instituição que tem uma missão muito bem definida desde a sua criação. 0 próprio conceito de laboratório nacional, laboratório aberto, provê um conjunto de instalações altamente sofisticadas para a comunidade científica.

Foi citado algumas vezes pelos entrevistados que um ponto fundamental no sucesso da instituição é o sistema de gestão do laboratório.

A gestão do LNLS é bem peculiar. É uma organização social através de um contrato de gestão com o MCT e que foi desenvolvido dentro do laboratório no ano de 1993, porque havia muita clareza que um laboratório como esse exige uma dinâmica de funcionamento que o modelo de administração direta, pública, não satisfaria.

Outro aspecto citado nas entrevistas é a forma de gestão dividida em duas décadas: até 1998 o LNLS era uma instituição de pesquisa com administração direta, vinculada ao CNPq. A partir de 1998 se cria, a partir de uma lei, uma organização social chamada Associação Brasileira de Tecnologia de Luz Síncrotron, que passa a ser a organização gestora do LNLS, organização privada, sem fins lucrativos que celebrou um contrato de gestão com o CNPq e MCT para operar essa entidade.

Ainda sobre o modelo de gestão, os entrevistados manifestaram que o modelo de gestão atual como organização social é um dos fatores de sucesso do laboratório. Poucas instituições do país na C\&T são geridas através do modelo de organização social.

Os entrevistados, de maneira geral, reconhecem como um dos aspectos positivos a autonomia de gestão da instituição, o que lhes permite ter seu próprio regulamento de compras e seu plano de cargos e salários, entre outros.

Com relação aos aspectos negativos, os entrevistados citam principalmente a dificuldade de compreensão, por parte de alguns órgãos do governo, que identificam o laboratório como terceirização.

Os entrevistados, de modo geral, abordaram aspectos relacionados com os indicadores incluídos no contrato de gestão com o ministério, notadamente o plano de metas que devem ser cumpridas durante o período da sua execução.

Nas respostas dos entrevistados, de modo geral, percebe-se uma abordagem diferenciada entre 0 sistema de avaliação utilizado para o cumprimento do contrato de gestão assinado com o MCT e as avaliações que são realizadas, em nível interno, junto aos funcionários da instituição.

Sobre a utilização das informações do sistema de avaliação, os entrevistados tentam desvincular o sistema de avaliação de desempenho existente na instituição com aspectos relacionados à remuneração, por exemplo, e à sua promoção dentro da empresa.

$\mathrm{Na}$ análise das entrevistas com os gestores do LNLS pode-se encontrar uma série de percepções sobre os temas que fizeram parte dos questionários, ocorrendo, às vezes, algumas contradições, talvez produto da situação híbrida da instituição que, sendo uma organização social privada, recebe financiamento do Estado através de contrato de gestão com o MCT.

\section{Contribuições para a gestão estratégica de instituições de C\&T}

Com base nas configurações, e na literatura pesquisada, a perspectiva idealizada tem a capacidade de identificar uma forma de gestão e planejamento, baseada em uma das configurações de Mintzberg et al. (1995; 2006), a adhocracia, integrada a um sistema de avaliação do desempenho de uma empresa, em termos de sua propensão e 
tendência ao longo do tempo. Assim, os indicadores definidos terão que ter o poder de demonstrar, além de um número que reflita o que ocorreu num dado período de tempo ou momento anterior, condição de antever para onde a empresa estará se dirigindo dada a propensão e tendência implícitas nos indicadores.

A perspectiva proposta de gestão e planejamento, adotando a configuração da adhocracia, deve necessariamente ser complementada por um sistema de avaliação de desempenho dirigido, respeitando suas características e que permita uma análise adequada dos seus problemas, através de um elenco de indicadores compatíveis com suas funções e as estratégias de uma instituição tão específica.

A Figura 4 representa graficamente a alternativa proposta.

Considerando que as instituições de ciência e tecnologia enfatizam aspectos mais ligados ao desempenho técnico das suas equipes, a seu aprendizado e aos processos internos, mais do que a seus aspectos financeiros - pois na maioria dos casos existe o financiamento através de agências do estado -, é que o autor escolheu adotar Balanced Scorecard como sistema de avaliação de desempenho para constituir a alternativa proposta, porém com algumas alterações relativas à utilização das suas expectativas conhecidas.

Propõe-se que a perspectiva de gestão estratégica a ser desenvolvida neste trabalho apoie-se na configuração adhocracia, de Mintzberg, baseada em duas perspectivas do Balanced Scorecard: perspectiva dos processos internos ou operacionais e perspectiva do aprendizado e crescimento; e uma terceira perspectiva adaptada pelos autores, perspectiva dos processos administrativos, para ser aplicada em instituições de ciência e tecnologia com a identificação, ainda, dos principais stakeholders.

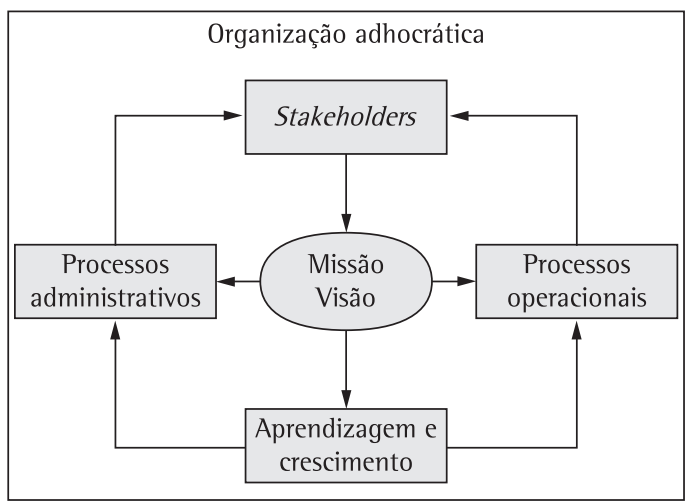

Figura 4. Perspectiva proposta para gestão de instituições de C\&T. Fonte: primária dos autores.
A parte central deste trabalho envolve a determinação de uma perspectiva de gestão estratégica para ser aplicada em instituições de ciência e tecnologia. Para verificar a possibilidade de aplicação da perspectiva desenvolvida foi realizado um teste de aplicabilidade em uma instituição de ciência e tecnologia, através de pesquisa junto a seus principais executivos.

Em termos de proposta de gestão para instituições de ciência e tecnologia, o que pode ser considerado mais próximo para integrar a perspectiva em estudo é a configuração de Mintzberg conhecida como adhocracia, pelas suas próprias características:

- Seu principal mecanismo de coordenação é o ajustamento mútuo;

- A parte-chave da organização é a assessoria de apoio (na adhocracia administrativa, juntamente com o núcleo operacional na adhocracia operacional);

- Os principais parâmetros para delinear são os instrumentos de interligação, estrutura orgânica, descentralização seletiva horizontal, especialização do trabalho, treinamento, agrupamento concorrentemente funcional e por produto; e

- Os fatores situacionais são um ambiente complexo e dinâmico (algumas vezes dessemelhantes), jovem (especialmente a adhocracia operacional), sistema técnico sofisticado, muitas vezes automatizado (na adhocracia administrativa), e segue a moda.

\section{Conclusões}

0 presente trabalho estabeleceu como seu objetivo geral contribuir para a construção de uma perspectiva de gestão estratégica para instituições de ciência e tecnologia baseada em sistemas de medição de desempenho que atenda os interesses de seus stakeholders.

Primeiramente pode ser concluído que a revisão da literatura representou informações relevantes na elaboração da perspectiva proposta de gestão estratégica para instituições de ciência e tecnologia.

0 levantamento dos conceitos sobre gestão estratégica e sobre modelos de gestão permitiu organizar as ideias em torno de uma base que possibilitasse a elaboração de uma proposta de gestão para as instituições tema do estudo.

$\mathrm{Na}$ comparação das características de cada uma das configurações de organização apresentada por Mintzberg, e sempre considerando a sua afinidade e compatibilidade com as instituições de ciência e tecnologia, os autores optaram pela configuração adhocracia por se tratar da mais adequada a esse tipo de organização. 
Dentre os sistemas de avaliação de desempenho foi escolhido o BSC como conceito básico que oferece, além da perspectiva financeira, as perspectivas dos clientes, dos processos internos e de aprendizado e crescimento.

$\mathrm{Na}$ hora de compor a proposta de gestão estratégica no estudo foram escolhidas as perspectivas dos processos internos ou processos operacionais e de aprendizado e crescimento; por oferecerem características mais adequadas ao tipo de instituições de ciência e tecnologia que, na maior parte das entidades, é financiada pelo setor público, através de agências de fomento como o CNPq, ou diretamente pelo MCT.

Os autores consideraram também a utilização de uma perspectiva denominada de processos administrativos que possibilita o estabelecimento de indicadores nessa área, principalmente no nível de conhecimento dos sistemas de avaliação de desempenho, nesse caso especificamente sobre o BSC.

A revisão da literatura permitiu também maior conhecimento das instituições de ciência e tecnologia, principalmente referente à política de C\&T e gestão de instituições de C\&T no Brasil, o que representou uma boa base de raciocínio para entender melhor a natureza e características peculiares desse tipo de instituição.

Os resultados do levantamento de campo e da análise dos dados de entrevistas completaram os dados da revisão bibliográfica com informações empíricas de indivíduos experientes que têm a responsabilidade pela gestão e aplicação das melhores ferramentas de administração encontradas.

Parte fundamental da proposta de gestão foi a pesquisa de campo efetuada em uma instituição de ciência e tecnologia, no caso no Laboratório Nacional de Luz Síncrotron e, mais tarde, a realização de entrevistas com os gestores dessa instituição para verificar a aplicabilidade da perspectiva proposta de gestão.

$\mathrm{Na}$ análise dos dados da pesquisa pôde-se chegar a algumas conclusões preliminares com relação às respostas dos questionários sobre aspectos dos processos internos, dos processos de aprendizado e dos processos administrativos contidos na consulta.

A cultura da organização apresentou-se como importante fator crítico, em especial no que se refere ao compartilhamento de informações e atitude em relação a possíveis mudanças no sistema de avaliação, assim como na consideração dos valores organizacionais.

Sobre a aplicabilidade da perspectiva de gestão proposta para a discussão dos gestores do
Laboratório Nacional de Luz Síncrotron, pode-se observar que apesar de algumas discrepâncias a proposta foi considerada aplicável com algumas adaptações em função das características, principalmente culturais, da instituição.

Os entrevistados, de maneira geral, percebem a proposta como algo interessante para ser aplicado, com algumas adaptações em função das características de cada instituição. Para tanto, a nova perspectiva deve ser mais conhecida, ver como ela se ajusta, melhorando o sistema de avaliação interna.

Por se tratar de um trabalho sobre gestão estratégica para instituições de ciência e tecnologia, em que a maioria delas recebe financiamento de órgãos públicos, CNPq ou MCT, e cada uma delas poderá apresentar uma forma de gestão condizente com as suas demandas, e considerando a complexidade e abrangência do tema, verifica-se que no atual estágio do conhecimento não é possível criar uma única forma de gestão que satisfaça todas as demandas das empresas do setor, de maneira efetiva, precisa e com a devida consistência e abrangência.

A partir dessa consideração, uma limitação que se apresenta para o trabalho é o fato de a proposta não contemplar uma ponderação do nível de importância para que cada instituição de ciência e tecnologia, ou de pesquisa e desenvolvimento, possa representar a nova forma de gestão com a integração dos conceitos apresentados.

No entanto, espera-se que tais limitações sejam superadas na medida em que a teoria sobre o assunto se desenvolva e se ampliem as aplicações práticas dessa proposta de gestão estratégica.

\section{Referências}

ANSOFF, H. I. A nova estratégia empresarial. São Paulo: Atlas, 1990.

BARDIN, L. Análise de conteúdo. Lisboa, 1977.

BERTERO, C. O. Gestão de Ciência e Tecnologia: uma análise institucional. PADCT 11, 1994.

CAVENAGHI, V.; BRUNSTEIN, l. Desempenho estratégico em manufatura: uma contribuição à estratégia de negócios. ln: SIMP01, 5., 2001, São Paulo. Anais...

DOWLING, D.; CLARK, J. Estatística aplicada. São Paulo: Saraiva, 2000.

FERRAZ, C. A.; MARTINS, R. A. Uma revisão sobre os métodos de diagnóstico da medição de desempenho. In: SIMPOI, 5., 2002. FGV EAESP

FERREIRA, A. A. et al. Gestão empresarial: de Taylor aos nossos dias. Evolução e tendências da moderna administração de empresas. São Paulo: Pioneira Thompson Learning, 2002. 
GODOY, A. S. Pesquisa qualitativa: tipos fundamentais. Revista de Administração de Empresas, v. 35, n. 3, p. 20-29, 1995.

G00D, W. J.; HATT, P. K. Métodos em pesquisa social. São Paulo: Nacional, 1969.

GUNTHER, H. Como elaborar um questionário. Instituto de Psicologia, UNB, 1999.

HAIR, J. et al. Fundamentos de métodos de pesquisa em administração. Porto Alegre: Bookman, 2005.

HAVE, T. S. et al. Modelos de gestão: o que são e quando devem ser usados. São Paulo: Pearson Prentice Hall, 2003.

HITT, M. A. et al. Administração estratégica: competitividade e globalização. São Paulo: Pioneira Thompson Learning, 2002.

KAPLAN, R. S.; NORTON, D. P. A estratégia em ação: balanced scorecard. Rio de Janeiro: Campus, 1997.

MINTZBERG, $H$. et al. Criando organizações eficazes. estruturas em cinco configurações. São Paulo: Atlas, 1995.

MINTZBERG, $H$. et al. Criando organizações eficazes: estruturas em cinco configurações. 2 ed. São Paulo: Atlas, 2006.

OLIVEIRA, S. L. Tratado de metodologia cientifica: projetos de pesquisas, TGl, TCC, monografias, dissertações e teses. São Paulo: Pioneira Thompson learning, 2002.
PEREIRA, A. B.; MIRANDA, A. Comunicação: ferramenta de marketing interno para novos modelos de gestão. In: ENCONTRO NACIONAL DE ENGENHARIA DE PRODUÇÃO, 27., 2007, Foz do lguaçu, PR.

SAllES, J. A. A. Gestão estratégica da manufatura. Tese (Doutorado)-FGV, EAESP, 1998.

SANTOS, L. A. C. et al. Controle de programa de P\&D em uma universidade através da gestão de portfólio. ln: ENCONTRO NACIONAL DE ENGENHARIA DE PRODUÇÃO, 27., 2007, Foz do lguaçu, PR.

SCHAEFER, D. R.; DILLMAN, D. A. Development of a standard e-mail methodology: results of an experiment. Public Opinion Quarterly, 1998.

SOUZA, G. S. E. et al. Eficiência técnica dos centros de pesquisa da Embrapa e fatores causais. In: ENCONTRO NACIONAL DE ENGENHARIA DE PRODUÇÃO, 27., 2007, Foz do lguaçu, PR. Anais...

ZILBER, M. A.; FISCHMANN, A. A. Competitividade e a importância de indicadores de desempenho: utilização de um modelo de tendência. ENANPAD, Salvador, BA, 2002. Anais...

ZOUAIN, D. M. Gestão de instituições de pesquisa. Rio de Janeiro: Ed. FGV, 2001.

\title{
Contributions for the strategic management for science and technology institutions
}

\begin{abstract}
This paper presents contributions for the strategic management for science and technology institutions, based on one of the Mintzberg configurations integrated to a performance evaluation system provided with indicators adapted to the nature of these organizational structure. To develop this perspective, have been performed a analysis of the existing literature about management designed and performance evaluation system, and about management for science and technology - S\&T institutions located in Brazil, mainly to identify of the stakeholders that's organizations; was applied a questionnaire with the research leaders in the S\&T institution selected, and were interviewed to their the managers, to check the results obtained and for discuss the applicability of the proposal to the management institution. The results obtained have demonstrated that this proposal of the a management system based on the adhocratic configuration associate with the performance evaluation system such as Balanced Scorecard, presents applicability in the science and technology institutions.
\end{abstract}

\section{Keywords}

Strategic management. Performance evaluation. Mintzberg configurations. Science and technology institutions. 